\title{
There is nothing to identity
}

\section{Oreste Fiocco ${ }^{1}$}

Received: 1 July 2020 / Accepted: 10 March 2021 / Published online: 12 April 2021

(C) The Author(s) 2021

\section{Abstract}

Several have denied that there is, specifically, a criterion of identity for persons and some deny that there are, for any kind, diachronic criteria of identity. I argue, however, that there are no criteria of identity, either synchronic or diachronic, for any kind whatsoever (and could be none). I begin by elaborating the notion of a criterion of identity in order to clarify what exactly is being denied when I maintain there are none. I examine the motivation of those who qualify in some way the general claim that there are synchronic and diachronic criteria of identity for every kind, then present my direct and categorical argument against such criteria. I next evaluate the objections of those who argue that rejecting criteria of identity has untenable results. These objections are ineffective, each based on the incorrect assumption that if there is no criterion of identity for a kind, the identity of an instance of that kind is independent of its qualities. I conclude by considering some of the upshots of rejecting criteria of identity and the insight doing so provides into things in general and the limits of ontological inquiry.

Keywords Identity · Criteria of identity · Anti-criterialism · Personal identity · Explanation · Ontology

\section{Introduction}

A criterion of identity is a putative ontological principle that is supposed to account for the identity of a thing. As such, it is the supposed basis of how a thing exists as itself, and so is taken to be the means of distinguishing that thing from others of the same kind. There are supposed to be synchronic criteria of identity, which are to account for the existence of a thing (as itself) at a single moment, and diachronic criteria, which are to account for the continued existence of a thing from one moment to another.

Criteria of identity have been part of the stock-in-trade of generations of the most eminent philosophers in the analytic tradition and so have come to be central to many

\footnotetext{
M. Oreste Fiocco

mfiocco@uci.edu

1 Department of Philosophy, University of California, Irvine, CA 92697-4555, USA
} 
metaphysical discussions. ${ }^{1}$ Thus, a plausible (synchronic) criterion for a given kind of thing is regarded by some as requisite to the very legitimacy of that kind. Recall Quine's concern about the number and features of the possibilia in his doorway ${ }^{2}$ and his slogan, "No entity without identity". ${ }^{3}$ More broadly, Peter van Inwagen's muchconsidered Special Composition Question, concerning when a plurality of things make a single one, ${ }^{4}$ can be construed as asking whether there is a (synchronic) criterion of identity for composite things in general. The search for a (diachronic) criterion has long been the mainspring of investigations of personal identity, which focus on what it is that makes one the same person over time. The issue of how things in general persist is thought to be resolvable by determining a (diachronic) criterion of identity for temporal entities.

Underlying these discussions (and others) is the presumption that the identity of things - at a moment or over time-is explicable, that there is some illuminating account of what makes a thing itself. Call the view that there are informative criteria of identity meeting this explanatory condition criterialism. Criterialism is widely accepted. Although several have denied that there is, specifically, a criterion of identity for persons ${ }^{5}$ and some deny that there are, for any kind, diachronic criteria of identity, ${ }^{6}$ both of these positions are compatible with there being at least some such criteria (e.g., for kinds other than persons or synchronic criteria). Here I defend the stringent view—call it primitivism - that there are no criteria of identity, either synchronic or diachronic, for any kind whatsoever (and could be none). I maintain that it is demonstrable that identity is inexplicable and, consequently, there are no ontological principles - no criteria of identity - that account for the identity of a thing. Hence, any metaphysical discussion premised on there being such is misguided. Some might think a defense of primitivism is otiose, for in influential work, David Lewis maintains that "Identity is utterly simple and unproblematic." " But if one looks at where Lewis makes this claim, one will see that it is a pronouncement rather than the conclusion of an argument. In this paper, I attempt to demonstrate why identity is unproblematic: there is nothing to it.

I begin by elaborating the notion of a criterion of identity in order to clarify what exactly is being denied when I maintain there are no such principles. I examine the motivation of those who maintain that criterialism can be accepted only with certain

\footnotetext{
1 The use of criteria of identity for various purposes has been so common that it seems almost silly to cite this use. For present purposes, however, it is perhaps worth noting that, in addition to those cited below and among many others, criteria of identity play a significant role in the work of P. F. Strawson (1959), Donald Davidson (1980), Saul Kripke (1980), Peter Geach (1980, 1972), David Wiggins (1980, 1967), Michael Dummett (1981, 1973), Timothy Williamson (1990), E.J. Lowe (1998) and Amie Thomasson (2007).

2 Quine (1953: p. 4).

3 Quine (1969: p. 23).

4 van Inwagen (1990).

5 See, for instance, Lowe (2012), Chisholm (1989, 1976), Swinburne (1985), Madell (1981). Earlier proponents of this position include Thomas Reid (Reid 1785, reprinted in Perry 2008) and Joseph Butler (Butler 1736, reprinted in Perry 2008).

6 See Merricks (1998) and, following him, Langford (2017). Matt Duncan (in Duncan 2020, 2014) calls Merricks' and Langford's position anti-criterialism. Note that this anti-criterialism is consistent with criterialism as I have defined the latter.

7 Lewis (1986: p. 192).
} 
qualifications, then present my direct and categorical argument against criteria of identity. In the following section, I evaluate the objections of those who argue that rejecting such criteria has untenable results. These objections are ineffective, each based on the incorrect assumption that if there is no criterion of identity for a kind, the identity of an instance of that kind is independent of its qualities. I conclude by considering some of the upshots of primitivism for certain metaphysical discussions and the insight the position provides into things in general and the limits of ontological inquiry.

\section{Why there can be no criteria of identity}

Frege is credited with introducing 'criterion of identity' into the philosophical lexicon. ${ }^{8}$ The use to which he originally puts the term is clearly semantic:

If we are to use the symbol $a$ to signify an object, we must have a criterion for deciding in all cases whether $b$ is the same as $a$, even if it is not always in our power to apply this criterion.

Frege suggests, here and in the passage immediately following, that unless one has such a criterion, one cannot refer to an object by a proper name. Consequently, criteria of identity might seem to be crucial to singular thought.

This initial characterization, which ties how one can speak and even think about the world to the availability of some criterion of identity, has led some to regard such criteria as epistemic principles. On this construal, a criterion of identity for some kind is the evidence that would justify one's judgments regarding the identity (or distinctness) of instances of that kind. Wittgenstein, whose use of a notion of criteria of identity in Philosophical Investigations certainly popularized such principles, seems to have understood these criteria in this epistemic way. ${ }^{9}$

Any semantic or epistemic view of criteria of identity is in contrast to an ontological one. On the latter, a criterion of identity is not the means of speaking about a unique thing or of justifiably taking it as such, but rather is what makes a given thing itself. Thus, a criterion of identity is some thing - in the broad sense in which a quality or relation or an entity of any category is a thing - that is the explanatory basis of how a thing is itself at one moment or over many. It is an ontological principle, not in being some representation of what it is that makes some thing itself, but in being the very thing that is supposed to do this. Both those who accept criterialism and those who maintain that the general view must be qualified take criteria of identity to be ontological principles; indeed, doing so is now standard in discussions to which such criteria are assumed to be relevant. ${ }^{10}$

\footnotetext{
8 Frege (1884: \$62).

9 See Wittgenstein (1953: §§253, 288 and 322), for instance.

10 See, for instance, Duncan (2020), Lowe (2009: pp. 18, 19), Zimmerman (1998: p. 281), Merricks (1998: pp. 108-109). Michael Della Rocca maintains that those who dispute how things persist nevertheless agree that there is some relation in virtue of which persistence occurs and, hence, that there is an ontological (diachronic) criterion of identity for temporal entities. See Della Rocca (2011: pp. 593, 594, 595).
} 
It is the claim that there are criteria of identity in precisely this ontological sense that I argue is demonstrably false. Rejecting such criteria is consistent with accepting epistemic criteria of identity, and this is appropriate for surely there are evidential grounds for one's judgments regarding identity. (Semantic criteria of identity along Fregean lines are symptomatic of an untenable intentional-cum-ontological position, or so I have argued elsewhere. ${ }^{11}$ )

\subsection{A categorical rejection of criteria of identity}

As noted above, there are those who reject the general view of criterialism (by qualifying it in one way or another). The reasons that have been given for rejecting the view are not mine. ${ }^{12}$ Nevertheless, Trenton Merricks' reasons for maintaining that there is no diachronic criterion of identity for any kind are worth considering, for they contrast in interesting ways with my own.

Merricks' overall strategy against criterialism is to argue that there is no good reason to accept (diachronic) criteria of identity. This indirect way of arguing leaves open whether, despite the considerations Merricks adduces, there is indeed some unrecognized compelling reason to accept such criteria for some (or all) kinds. Recent debate about criterialism, which has been largely motivated by Merricks' discussion, has turned on just this question. ${ }^{13}$ The argument I present against criterialism, however, is direct, showing not merely that there is no reason to accept (diachronic) criteria of identity, but why there is no reason, namely, because there are no criteria of identity - synchronic or diachronic, for any kind-and could be none.

After arguing that issues traditionally associated with diachronic criteria of identity present no reason for thinking there are such, ${ }^{14}$ Merrick observes that accepting such (diachronic) criteria commits one to necessary connections between seemingly contingent complex states of affairs. Thus, if $O$ persists from $m$ to $m^{\prime}$ in virtue of $C$ (a relation that is putatively criterial for identity over time for the kind of which $O$ is an instance), then necessarily $\mathrm{O}$ at $\mathrm{m}$ being identical to $\mathrm{O}^{\prime}$ at $\mathrm{m}^{\prime}$ obtains if, and only if, $\mathrm{O}$ at $\mathrm{m}$ and $\mathrm{O}^{\prime}$ at $\mathrm{m}^{\prime}$ being related via $\mathrm{C}$ does. The modal connection between these two complex states of affairs is supposed to be gratuitous since, as Merricks maintains, there is no good reason to accept any diachronic criterion of identity. If one assumes, as Merricks does, that one should avoid positing necessary connections unless there is

\footnotetext{
11 See Fiocco (2015).

12 One argument against a criterion of identity for human persons, in particular, is based on graduality: the most-familiar proposed criteria of personal identity are gradual, admitting of degrees, whereas personal persistence seems to be absolute and, hence, without degrees. Thus, proponents of (the most-familiar) criteria of personal identity are committed to the implausible claim that there is a precise point at which a gradual criterion suffices for identity. Another argument is based on fission cases, where one person comes to be physically, psychologically, biologically, etc. continuous with two. Fission is discussed in the text below. See Duncan 2020: $\$ 1$ for a presentation of the various considerations traditionally levelled against criterialism. See Gasser and Stefan (eds.) (2012: pp. 8-11) for an introductory discussion of the considerations broached in this note.

13 See, for example, the exchange in Duncan (2014, 2020), Langford (2017).

14 See Merricks (1998: $\S \S I I I-I V)$.
} 
some reason to do so, this unwarranted modal commitment of criterialism is significant reason to reject the view. ${ }^{15}$

Contrary to Merricks, I think there are good reasons to accept the sort of modal connection under consideration here. These reasons are based on an account of what a thing, in the most general sense, is and emerge from my argument against criterialism. These modal connections are, then, consistent with there being no criteria of identity. Ironically, recognizing the modal connections that Merricks regards as gratuitous as part of his argument against criterialism is central to responding to those who maintain that rejecting criteria of identity has untenable consequences. I return to this point below (in Sect. 3.1).

To reject criterialism, I first present a simple argument against synchronic criteria and then extend it to preclude diachronic principles. The upshot is that there are no criteria of identity whatsoever. Crucial to the argument is appreciating that criteria of identity are supposed to be informative. ${ }^{16}$ Informativeness is most straightforwardly construed as a feature of representational entities. As ontological principles, criteria of identity are not representational. However, a statement of what the criterion of identity for some kind is would be informative-insofar as one wished to know what made an instance of that kind itself-if it were explanatory, in the sense of being an account of that thing in virtue of which some other is itself (at one moment or from one moment to another).

Thus, a statement of the criterion of identity for some kind, $K$, would be informative (i.e., explanatory) only if it correctly characterized some relation between things in the world, one of which — the explanandum — is an instance of $K$ 's being itself and the other-the explanans - is the criterion of identity itself. (The relation must be one on which how the former is depends on or is determined by the latter.) I am assuming here a realist account of explanation, one on which any explanatory statement must be underlain by a determinative relation among things in the world. Unless there is such a basis, the explanation cannot be an accurate account of what it purports to be about (or anything else, for that matter). Such an understanding of explanation, it seems to me, is the only one suitable for theorizing about the things in the world. ${ }^{17}$

So consider what a realist explanation of the synchronic identity of a thing of kind, $K$, would require. What is to be explained is an instance of kind $K$ 's being itself at some moment, in other words, the explanandum is $a$ (at $m$ ) being identical to $b$ (at $m$ ). If there were some synchronic criterion of identity for $K$, this would be some relation, $R$, that holds between $a$ and $b$ (at $m$ ) such that standing in $R$ determines or makes $a=$ $b$. But there could be no such $R$. In order for a thing to stand in any relation whatsoever, that thing must exist. It must exist as the very thing it is: it must exist as itself. If this is so, it cannot be by standing in some relation that a thing is itself. Being itself is required for it to be related at all. Therefore, there cannot be any such relation in virtue of which $a$ is itself (i.e., $a=b$ ). Nor could there be, moreover, something of some

\footnotetext{
15 See Merricks (1998: §V). Simon Langford adopts this argument as his primary reason for rejecting diachronic criteria of identity. See Langford (2017: p. 614).

16 That criteria of identity must be informative is taken for granted in discussions of whether there are such criteria. See, for instance, Duncan (2020: p. 165), Merricks (1998: p. 107).

17 For a classic account of realist explanation, see Ruben (1990), especially Chapter 7. See, as well, Kim (1994: pp. 67-68).
} 
other category in virtue of which $a$ is itself, for were there such a thing, $a$ would have to be related to it, yet, as just demonstrated, $a$ must be itself in order to be related at all. Consequently, there can be no ontological principle that makes $a$ itself at a moment. This argument is completely general, so there are no synchronic criteria of identity.

This result can be confirmed by considering the issue in a different way. If $a$ and $b$ are not identical at $m$, then there is no relation in which they might stand-nor any other thing - that could render them so. Yet if $a=b$ (at $m$ ), it is not by some relation, nor any other thing, that $a$ is made to be itself, for $a$ must be itself if it exists at all (and it must exist prior to standing in any relation). Thus, again, there are no criteria of synchronic identity.

An argument just slightly more complicated than the foregoing demonstrates that there are no diachronic criteria of identity either. What is to be explained by these principles is an instance of kind $K$ 's being itself at distinct moments, to wit, $a$ at $m$ being identical to $b$ at $m^{\prime}$. If there were some diachronic criterion of identity for $K$, this would be some relation, $R$, that holds between $a$ at $m$ and $b$ at $m^{\prime}$ such that standing in $R$ determines or makes $a($ at $m)=b\left(\right.$ at $m^{\prime}$ ). If $a($ at $m)$ and $b$ (at $m^{\prime}$ ) were distinct, then there could be no relation such that standing in it determines $a$ (at $m)=b\left(\right.$ at $\left.m^{\prime}\right)$; no relation — or thing of any category — could make distinct things one and the same. So were $R$ a relation that accounts for the identity of $a$ at $m$ and $b$ at $m^{\prime}$, it must be the case that $a$ at $m=b$ at $m^{\prime}$. In other words, were there a diachronic criterion of identity for some kind, $K$, at all, it could only hold between one and the same instance of $K$ at distinct moments. But then a prerequisite for there being a criterion of identity for $a$ at $m$ and $b$ at $m^{\prime}$ is that $a$ at $m=b$ at $m^{\prime}$. Therefore, it cannot be in virtue of this relation, $R$, that $a(b)$ is itself over time. $R$ is not a criterion of identity. This argument, too, is completely general, and so there are no diachronic criteria of identity.

This result can also be confirmed by considering the issue in a different way. A thing, $a$, at moment, $m$, need not persist; if $a$ is a temporal entity, $m$ might be the last moment at which $a$ exists. But if $a$ does persist, it must continue as itself: it could be no other thing. Hence, if $a$ at $m$ is not identical to $b$ at $m^{\prime}$, then there is no relation in which they might stand - nor any other thing - that could render them so. Yet if $a$ (at $m)=b\left(\right.$ at $\left.m^{\prime}\right)$, it is not by some relation (nor any other thing) that $a(b)$ is made to be itself, for $a(b)$ must be itself if it exists at all. Thus, again, there are no criteria of diachronic identity.

These considerations against diachronic criteria of identity presume endurantism, the view on which a thing persists by being wholly present at distinct moments. One might try to undermine their conclusion by rejecting this view of persistence. Such a defense of diachronic criteria of identity, however, would not be effective. Even if perdurantism were correct, and so a thing persists in virtue of having distinct temporal parts at distinct moments, there would be no such criteria. To see this, assume a thing, $A$, persists by perduring. $A$ itself, the temporally-extended whole of it, is the sum of its parts existing at different moments. A diachronic criterion of identity for a perduring thing such as $A$ would be some relation, $R$, holding between the momentary temporal parts of $A$, for example $a$ (at $m$ ) and $b\left(\right.$ at $m^{\prime}$ ), that is the ontological basis of an explanation for why both are parts of $A$. Thus, it would be in virtue of $R$ that $a$ (at $m$ ) and $b$ (at $m^{\prime}$ ) are both (temporal) parts of $A$. However, $A$ must exist in order for anything to be related to it and, a fortiori, to be part of it. If this is so, a prerequisite of $R$, the 
relation that accounts for a thing being part of $A$, holding is the existence of $A$ itself. $A$ is a temporally-extended whole comprising temporal parts at distinct moments. Therefore, it cannot be in virtue of $R$ that $A$ exists as itself at distinct moments, that is, has the parts it does at the various moments of its career. $R$ is not a criterion of identity; there can be no such criteria for perduring things.

The foregoing is an application of a general argument I have presented elsewhere against the claim that there could be some thing (for example, a form or a relation) that accounts for the unity of a complex whole. ${ }^{18}$ Regardless, then, of whether a thing persists by enduring or perduring, there is no ontological principle that underlies an explanation of the existence of that thing through time. ${ }^{19}$ I conclude again that there are no diachronic criteria of identity.

There are, therefore, no criteria of identity, either synchronic or diachronic, for any kind of entity. ${ }^{20}$ There is nothing to identity: There is no thing, no ontological principle, that makes a thing be itself at one moment or over many. In light of the simplicity of the preceding arguments, this categorical conclusion seems obvious, even indisputable. Its being overlooked might be explained by a failure to appreciate what an ontological criterion of identity would have to be or, relatedly, that any informative (i.e., explanatory) account of the identity of a thing — synchronic or diachronic — would have to rest upon an ontological basis of things in the world standing in some relation. Being identical to itself is attendant upon the very existence of a thing and so is beyond explanation in terms of some other thing and is, in this sense, primitive. Likewise, persisting is a capacity attendant upon the very existence of any temporal entity that exists at more than one moment and so, too, is beyond explanation and primitive. In neither case is identity some thing beyond the existence of a thing, so, in this sense too, there is nothing to identity.

\footnotetext{
18 See Fiocco (2019a).

19 I set aside here consideration of stage theory, which some regard as a view of persistence. On this view, no thing exists, or has parts, at more than one moment (although a thing at one moment might have some proxy at a distinct one and, to this extent, be said to exist at both moments). In the context of this discussion of diachronic criteria of identity, I assume that things do indeed exist at distinct moments.

20 I noted above (see footnotes 5 and 6) that certain philosophers maintain that not all kinds have a criterion of identity. A notable recent example is E.J. Lowe, who holds that the identity at least of persons and of fundamental particles is probably "primitive and "simple"" (Lowe, 2012: p. 152). To illuminate the primitivism for which I am arguing, it might be helpful to contrast my view with Lowe's. The two are actually quite different, in content and motivation. Although Lowe believes that persons and fundamental particles - and any other kind similarly "basic in our ontological scheme" — do not have a criterion of identity, he accepts that many, if not most, kinds do. Contrariwise, I argue that no kind whatsoever (thus, regardless of ontological scheme or the place of a kind in such a scheme) has a criterion of identity. Moreover, Lowe's argument for the primitivism of the identity of persons is indirect and inductive. He argues for it by undermining certain complex accounts of personal identity and, since he has not considered all possible complex accounts, settles for the probable truth of his conclusion that the identity of persons is primitive. My argument for primitivism, on the other hand, is direct and deductive. On the basis of plausible assumptions about explanation, relations and existence, I maintain it follows that no kind could have a criterion of identity.
} 


\subsection{What a thing is}

The argument that demonstrates the primitiveness of identity turns on the fact that a genuinely explanatory account of any phenomenon requires an ontological basis of things in some determinative relation. There is the phenomenon to be explained and some thing or things related to it that realize the explaining. It is in virtue of the latter that the former is as it is. In light of this, things are the means of explanation-yet they are also its limit. If (at least) one thing must be related to at least one other in order for there to be an explanation at all, a thing itself and whatever is attendant upon the very existence of that thing is beyond explanation. For were that thing (or whatever is attendant upon it) to be explained, it must exist and, hence, be as it is simply by existing, to stand in the determinative relation requisite for explanation. Therefore, it cannot be in virtue of this relation, or its other relata, that that thing exists or is as it is merely in being.

I have applied the general argument just sketched in a number of ways to gain insight into what a thing, in the most general sense, is. The arguments propounded above demonstrate that there is no explanation for the identity of a thing. Elsewhere, I have used similar arguments to show that there is no ontological basis of an explanation for the existence of a thing (its present existence as opposed to how it came to be); its individuation, i.e., what makes that thing the very thing it is; its unity, if it is complex; why it is what it is or why it is essentially as it is. These phenomena are not merely unexplained, but inexplicable in that they are not even susceptible to (robust, realist) explanation. There is no explaining a thing per se; consequently, there is nothing that grounds or makes up or otherwise yields ontologically some other thing. On this basis, I maintain that each thing, regardless of kind or category, is fundamental. ${ }^{21}$

This conclusion that each thing is fundamental does not, in itself, provide any insight into what things or what kinds of thing are in the world. Nevertheless, the fundamentality of all things does provide grounds for accepting that oneself, one's mental states and the various things one confronts when engaging the world, be they qualitative or non-qualitative, universal or particular, are all fundamental. Any thing that prompts inquiry exists and, hence, is fundamental, as are all things that can stand in any relation to what prompts inquiry. Thus, if one encounters a table or tree and one encounters (or otherwise admits) fundamental particles, one ought to regard all of these as equally real and fundamental. One might wonder about the relations between, say, a given table and some fundamental particles-presumably the former cannot exist in the absence of the latter, and so there is some relation of dependence between such things - but there should be no question of the table being or being reducible to or somehow being explicable in terms of the fundamental particles.

It does not follow from the fundamentality of each and every existent that there are no explanations. What can be explained, and sometimes is, are many of the actual arrangements of things, more specifically, those arrangements that need not be so, merely given the existence of the things so arranged. What does follow, though, is an account of what a thing, anything at all, is. Any thing is some ways and not others, and so is constrained. A thing is constrained at least insofar as it must be itself, the

21 See Fiocco (2019a). 
very thing it is, and must be what it is and the ways that things of that kind (or category) are essentially. If there is no thing that accounts for the identity of a thing or its individuation or what it is or how it is essentially, the constraints on that thing are inherent to it. The constraints arise from the thing itself. What a thing is, then, is a locus of constraint in the world, a natured entity: something that must be as it is essentially - and so must interact with other things as required by its being these ways-just by existing. The world comprises all the things there are and these things, including the relations among them, are the structure in the world.

In other work, I have derived this account of things as natured entities via consideration of inquiry itself. ${ }^{22}$ There, I address concerns about the inevitable circularity involved in providing a real definition of a thing. If one remains concerned about the adequacy of this account of any existent, those concerns can be set aside here. For present purposes, what is more important than what a thing is is how each is, namely fundamental. The fundamentality of each thing provides the basis for responding to those who maintain that rejecting criteria of identity has absurd or otherwise unacceptable consequences.

\section{Why the rejection of criteria of identity is not untenable}

Proponents of criteria of identity, like those eminent philosophers cited above, never argue directly that there are such things. Rather criteria of identity are simply taken for granted, as part of the heritage of analytic philosophy, and supposed to be useful in solving certain problems or illuminating certain phenomena. However, I have propounded a straightforward argument that there can be no such criteria. It would be inappropriate, then, merely to presume there are.

When considering the arguments of those who would qualify criterialism, proponents of the view in its full generality have tried to show that rejecting a criterion of identity for some kind leads to unacceptable consequences. Were there these consequences, they would indicate that the primitivism I am proposing is incorrect. There is a hypothetical scenario, presented by a number of philosophers, that is supposed to reveal these unacceptable consequences. If one rejects criteria of identity, the scenario, which seems impossible or at least extremely dubious, is supposed to be possible, burdening the primitivist with untenable commitments. Thus, showing that the primitivist is committed to the possibility of this scenario is the primary defense of criterialism. In this section, I examine the scenario, as well as related epistemological objections and one pertaining to the putative possibility of fission, to show that none of these considerations provides reason for thinking that rejecting (all) criteria of identity is problematic.

\subsection{The primary defense of criterialism}

Defenders of criterialism maintain that rejecting a criterion of identity for some kind commits one to the possibility of a clearly absurd, unacceptable scenario. Consider,

22 Fiocco (2019b). 
then, some thing, $o$, an instance of some kind. There are ever so many qualitative relations that hold between $o$ at moment, $m$, and $o$ at a distinct moment, $m^{\prime}$, when $o$ persists from $m$ to $m^{\prime}$. Depending on what kind of thing $o$ is, these relations might be spatial, physical, phenomenal, psychological, biological, chemical, etc. Consider next $o$ at $m^{\prime}$ and $x$, an instance of the same kind, at $m^{\prime \prime}$, where all the same relations that hold between $o$ at $m$ and $m^{\prime}$ (when it persists) hold between $o$ and $x$. If there is no criterion of identity among these familiar qualitative relations, then, the defender of criterialism holds, these relations are insufficient to themselves guarantee that $o$ (at $\left.m^{\prime}\right)=x\left(\right.$ at $\left.m^{\prime \prime}\right)$. If this is the case, it is supposed to be possible that all these relations hold between $o$ (at $m^{\prime}$ ) and $x$ (at $m^{\prime \prime}$ ), yet $o$ fail to persist. In other words, although $o$ and $x$ are qualitatively related and, hence, continuous in these respects, at distinct moments in every way that $o$ is when it in fact persists, it is nevertheless possible that $o \neq x$. Hence, there might be no qualitative differences in the world from $m$ to $m^{\prime}$ to $m^{\prime \prime}$, yet $o$ persist from $m$ to $m^{\prime}$ and fail to from $m^{\prime}$ to $m^{\prime \prime}$. Were this so, and $o$ were, say, a person, it would be possible for $o$ to be phenomenally, psychologically, spatially, physically, biologically—what have you — continuous from one moment to the next with a distinct person. But this is clearly absurd (and has demonstrably false consequences). Since the scenario is wholly general, with the denial of any criterion of identity leading to absurdity, these considerations are taken to demonstrate the falsity of primitivism.

Such reasoning is employed by a number of philosophers in defense of criterialism. ${ }^{23}$ What the key scenario is supposed to reveal is that one who denies a criterion of identity for some kind must regard the identity of an instance of that kind as independent of what and how that thing is. As it is sometimes put, identity "floats free" 24 from the qualities of a thing and, hence, from any qualitative relations or continuity. One who rejects a criterion of identity for some kind is supposed to hold that the (diachronic) identity of an instance of that kind is a "further fact" 25 beyond those about the qualitative relations of that thing or "something over and above" 26 these relations. It is for this reason that $o$ at $m$ and $m^{\prime}$ and $o$ at $m^{\prime}$ and $x$ at $m^{\prime \prime}$ can be as qualitatively continuous as can be and yet $o$ fail to persist from $m^{\prime}$ to $m^{\prime \prime}$, though it does persist from $m$ to $m^{\prime}$.

One might take this line of argument to show that those who reject criteria of identity are committed to there being some non-qualitative entity, a haecceity, that accounts for the identity of a thing at a moment and, hence, some relation involving this haecceity — some non-qualitative, haecceitistic relation - that accounts for the identity of a thing at distinct moments. This, however, is mistaken. The primitivism I am urging, in light of the arguments in Sect. 2.1 above, does not commit one to haecceities. Indeed,

\footnotetext{
23 See Duncan (2020: §3), Shoemaker (2012: p. 126), and Zimmerman (1998: pp. 287-288).

24 See, for example, Duncan (2020: §3) and Langford (2017: p. 614). Langford, who rejects diachronic criteria of identity, accepts that the identity of a thing is independent of how that thing is. As becomes clear below, I think this is mistaken.

25 Duncan (2020: §3).

26 Shoemaker (2012: p. 126).
} 
given those arguments, the primitivist should reject such entities. ${ }^{27}$ The arguments demonstrate not that there is some non-qualitative thing that accounts for the identity of something, but rather that nothing at all does, no thing could. A thing's being identical to itself is no thing; a fortiori, it is nothing over and above that thing. Consequently, a thing's being identical to itself is not distinct from how that thing is qualitatively (at a moment or at distinct ones); nor, arguably, some further fact than the existence of that thing (though resolving this issue turns on what exactly a fact is). Identity is not independent of what and how a thing is - it does not and cannot "float free". Appreciating this point is crucial to recognizing that, despite the claim of the criterialist, the primitivist is not committed to the possibility of the absurd scenario above.

Since each thing is fundamental, it just is what it is and how it is essentially. How a thing is when it persists is so closely associated with what that thing is-be it material, living, mental, etc. - that it is plausible that among the ways that thing is essentially are how it is when it persists. Instances of different kinds might stand in different qualitative relations to themselves when they persist, but any instance of a given kind must stand in exactly the same (range of) qualitative relations when it persists as does any other instance of that kind. ${ }^{28}$ If an instance of that kind stood in exactly those qualitative relations, then it could not fail to persist. This is because what that thing is is an instance of a kind that is exactly those ways when it persists. It would have to be a different kind of thing to be exactly those ways and yet fail to persist. No thing, however, could be a different kind of thing than what it in fact is. Therefore, if all the qualitative relations that hold between $o$, an instance of some kind, and itself when $o$ persists hold between $o$ and $x$, an instance of the same kind, then $o$ must persist, that is, it must be the case that $o=x$. The hypothetical scenario in which exactly these qualitative relations hold yet $o \neq x$ is, then, not possible.

There are, then, necessary and sufficient conditions for the persistence of things, yet this is consistent with there being no diachronic criteria of identity. Given that a thing, an instance of some kind, is essentially certain ways, there are necessary conditions for its persistence. Moreover, there is at least one sufficient condition for its persistence: being continuous in all the ways (that is, standing in all the same qualitative relations) that an instance of that kind is (or does) when it persists. Thus, if $o$ and $x$ are instances of the same kind, existing at distinct moments, and are continuous in all the ways that an instance of that kind is when it persists (ways that are, presumably, among those essential to such instances) then, necessarily, $o=x$. But, together, these necessary and sufficient conditions are not explanatory and, hence, not informative in the way that criteria of identity are supposed to be. It is not because a thing is as it is essentially and is continuous in all the ways that an instance of that kind is when it persists that it persists; rather, such necessary and sufficient conditions for the persistence of a thing are mere consequences of the primitive persistence of that thing.

\footnotetext{
27 Langford, an opponent of criterialism, maintains that haecceities are consistent with his position. See Langford (2017: p. 614). As noted above, my reasons for rejecting (diachronic) criteria of identity are different from Langford's.

28 Instances of the same kind need not stand in exactly the same qualitative relations when they persist, for instances of the same kind can have (somewhat) different qualities. Nonetheless, the range of these qualities, and the possible differences between the particular instances of the qualities from one moment to the next, must be the same for all instances of that kind.
} 
Matt Duncan claims that if primitivism "is true, then no amount of qualitative continuity of any kind is sufficient to guarantee any [thing's] persistence through any period of time." 29 This captures the crux of the criterialist's defense and is supposed to be what the hypothetical scenario illustrates. The claim, though, requires some care in interpretation because 'guarantee' is ambiguous. Although it is not in virtue of any one or all of the qualitative relations in which a thing of some kind stands to itself at distinct moments that that thing exists at those moments, any instance of that kind that stands in those relations persists. There is a necessary-essential—correlation, given what that thing is, between just those qualitative relations holding between that thing and itself at distinct moments and that thing existing at those moments. Note that the modal connections arising from this essential correlation, which I take to be pivotal to understanding and defending primitivism, are just the sort that Merricks regards as gratuitous in his argument for rejecting (diachronic) criteria of identity. Although no qualitative relation(s) guarantees persistence in the sense of being the ontological basis of an explanation for that persistence, those qualitative relations nonetheless guarantee persistence in the sense that they could not be present and an instance of that kind fail to persist. It is because no qualitative relation (or all of them together) can explain the persistence that no such relation is a (diachronic) criterion of identity.

I conclude, then, that the primary defense of criterialism, which turns on the possibility of a scenario that I have shown to be impossible, is not successful. It provides no reason to think that rejecting criteria of identity is problematic, and so in no way undermines primitivism.

\subsection{Related epistemological objections}

Defenders of criterialism also maintain that if one rejects (diachronic) criteria of identity, one is confronted with significant epistemological problems. ${ }^{30}$ The problems are supposed to arise because whether a thing develops or grows or changes in general depends on whether it persists, and so one's judgments about whether a thing, say, changes are based on the evidence one has that that thing persists. Such evidence is assumed to be the experience one has of the qualitative relations that hold between a thing and itself at distinct moments. If, however, there is no criterion of identity among these qualitative relations, then, it is claimed, it is possible for all of them to hold and an instance of the relevant kind nevertheless not persist. Consequently, experience of these qualitative relation does not suffice to know that one and the same thing changes - and if such evidence does not suffice, none does.

Sydney Shoemaker states the objection in this way:

[W]hat we can establish empirically about a series of thing-stages is insufficient to establish that it is the career of a persisting object... What more could I observe, or otherwise establish, that would show me that there really was a single persisting [thing] throughout that interval? It is hard to see how on this

\footnotetext{
29 Duncan (2020: §3). Italics in original.

30 See, for example, Duncan (2020: §3), Shoemaker (2012: p. 126), and Zimmerman (1998: pp. 292-293). For a very different approach to the one I am proposing to these epistemological objections, see Langford (2017: §§4-6).
} 
view [i.e., primitivism] we could have any justified beliefs about the persistence of [things] through time. ${ }^{31}$

Duncan tries to strengthen this sort of epistemological objection. He maintains that one has certain knowledge of one's own persistence based on one's introspective experience, yet, if primitivism is true "all of the physical and/or mental conditions upon which your first-personal evidence (i.e., your experiences) depends could possibly obtain without you persisting." 32

Obviously, these epistemological objections are based on the assumption that the hypothetical scenario discussed above is possible and, hence, all the qualitative relations that hold between $o$, an instance of some kind, and itself when $o$ persists can hold between $o$ and $x$, an instance of the same kind, and yet $o$ fail to persist. I have argued, though, that this scenario is in fact impossible. If this is so, then there is no reason to call into question the evidence usually taken to underlie one's knowledge regarding persisting things, including oneself. Therefore, such epistemological objections do not challenge primitivism.

\subsection{The putative possibility of fission}

From Michael Della Rocca's discussion of persistence in general, in which he examines the controversy between endurantists and perdurantists, one can infer an argument against the position that there are no (diachronic) criteria of identity. ${ }^{33}$ Central to this argument is the following principle:

(PPP) In a case in which there are objects $A, B$, and $C, B \neq C, B$ and $C$ are equally and significantly causally and qualitatively continuous with $A$, and there is no object besides $A$ which exists at the same time as $A$ and which is such that $B$ and $C$ are as causally and qualitatively continuous with it as they are with $A$, then it cannot be the case that $A=B$ and $A \neq C$ and it cannot be the case that $A$ $\neq B$ and $A=C$. $^{34}$

Della Rocca regards this principle as "extraordinarily plausible" and indeed takes any position incompatible with it as ipso facto unacceptable.

Consider now a case in which $A$, an instance of some kind, $K$, undergoes fission, yielding $B$ and $C$, distinct instances of that same kind. $B$ and $C$ both are supposed to stand to $A$ in whatever qualitative relations instances of this kind stand when such things persist. If there is no (diachronic) criterion of identity for $K$, then, Della Rocca assumes, the identity of a thing of that kind is independent of any qualities it has and any qualitative relations in which it stands. If this were so, then it would be possible for $A$ to be identical to $B$ and distinct from $C$ (or vice versa). This is inconsistent with PPP and is, then, supposed to show that it cannot be the case that there is no criterion

\footnotetext{
31 Shoemaker (2012: p. 126).

32 Duncan (2020: §3).

33 See Della Rocca (2011).

34 See Della Rocca (2011: p. 599). "PPP” stands for Parfit's Plausible Principle because of the importance of the principle to Derek Parfit's discussion of personal identity.
} 
of identity for $K$. The argument, of course, is wholly general, and so can be regarded as support for criterialism, the view that for any kind there is a (diachronic) criterion of identity for that kind.

I have argued that it is incorrect to maintain that identity is independent of what or how a thing is, that it, as it were, floats free from the qualities and qualitative relations of a thing. The identity of a thing is nothing at all and so is not something distinguishable from that thing. Hence, there are no grounds for claiming that if there is no criterion of identity that it is possible for $A$ to be identical to $B$ and distinct from $C$ (or vice versa) in violation of PPP. Della Rocca is mistaken in thinking that primitivism commits one to rejecting this plausible principle. However, the primitivism I defend, on which each thing is fundamental, does seem to be objectionable on other grounds. I hold that given that each thing is essentially how it is when it persists, that it follows that any instance of a kind that stands in the qualitative relations that such things stand in when they persist itself persists. If this is so, then when $A$ undergoes fission, $A$ persists-as both $B$ and $C$. But $B$ and $C$ are distinct. Since persistence implies identity and no thing is identical to two, $A$ persisting as both $B$ and $C$ is incoherent, an impossibility.

I believe the appropriate response to this impossibility is to deny that persistence is compatible with fission: if a thing splits into two qualitatively indistinguishable others, the first ceases to be. This is certainly plausible enough when considering an instance of a simple kind of thing, such as an amoeba. The position is supposed to be less plausible, leading to quite unintuitive results, when considering an instance of a much more complex kind, such as a human person. I think these unintuitive results should be avoided by rejecting that it is genuinely possible for complex kinds, such as human persons, to undergo fission. Indeed, there is no basis, beyond mere tradition, to accept such possibility. Accepting that a human person can undergo fission is de rigeur in certain contexts, like discussions of personal identity, but this seems to me to be just more of the heritage of analytic philosophy that does not withstand fresh critical scrutiny. This is not the place for a thorough discussion of these issues. I have said enough, I hope, to show that concerns about fission do not provide conclusive grounds for the claim that rejecting criteria of identity is untenable and, hence, do not threaten primitivism. ${ }^{35}$

\section{Conclusion: primitivism and its consequences}

Synchronic criteria of identity are supposed to have certain uses and are taken for granted in many discussions: for an instance of any kind there is presumed to be some thing that accounts for that instance being itself at a moment. Given this thing, the criterion of identity, one is supposed to be able to distinguish one instance of a kind from another, and count those instances if need be. Since such criteria are simply taken

\footnotetext{
35 It is interesting to note that fission cases have a contentious role in discussions of criteria of identity. Some, like Della Rocca, take fission to support criterialism, others take it to challenge this general view. Merricks and, following him, Duncan are among the latter. They argue that if there were a criterion of identity for some kind, and an instance of that kind underwent fission, then one would be committed to the contradictory result that one thing persists as two. [See Merricks (1998: p. 120 and Note 16)]. As is clear from the text above, I disagree with Merricks (and Duncan) on this point.
} 
for granted, there are no positive reasons to consider for thinking they exist. No one has ever denied them, so there are no defenses of synchronic criteria of identity to consider either. Therefore, the above argument for the conclusion that there are no and could be no synchronic criteria of identity for any kind presents an urgent and unimpeded challenge to those who believe there are such.

Diachronic criteria of identity are more controversial: some deny that there is a criterion for certain kinds, such as human persons, while others have argued that there are no diachronic criteria at all. These rejections of such criteria (and discussion of related matters) have led some to produce arguments that there must be diachronic criteria of identity. I have considered these in the preceding section and have found that they provide no reason at all to think that primitivism is false. All the objections to rejecting (diachronic) criteria of identity ultimately turn on the claim that if there is no such criterion for some kind, the identity of an instance of that kind is independent of what or how that thing is. This claim, however, is false. Identity is not independent of what or how a thing is; it is no thing at all and so is neither independent of nor dependent on anything. None of the objections, then, presents any reason to think that rejecting criteria of identity is untenable.

Therefore, I conclude that there are no criteria of identity, either synchronic or diachronic, for any kind whatsoever (and could be none). Primitivism is correct. Each thing just is (itself) at any moment; when a thing persists, it just is (itself) at distinct moments. This conclusion has many significant consequences. In closing, I briefly consider some.

If primitivism is correct, and there is nothing to identity and, hence, no explaining it, then any discussion premised on the assumption that the identity of a thing is indeed explicable is misguided. The most obvious example of such discussion concerns personal identity or, more specifically, personal persistence. The question of in virtue of what a person is the same over time has been explored since the beginning of Western philosophy. Different answers have been offered, most commonly, some sort of mental continuity or some sort of bodily continuity. But neither sort of answer-nor any other-will do, for there is nothing in virtue of which a person persists. A person, like any other thing, is fundamental. Nothing follows from this, however, about what exactly a person is; in particular, it does not follow that persons are in any way simple. A fundamental thing might be extremely complex, so even though there is nothing to account for the persistence of a person, a person need not be a simple soul or immaterial substance.

Primitivism indicates that any attempt to determine in virtue of what instances of some kind persist is futile. Nevertheless, the view does not provide any insight into how things exist through time in general, that is, primitivism provides no insight into which account of persistence is correct. Della Rocca maintains that any account of persistence that entails that it (or identity) is primitive is incorrect. Recognizing this is supposed to be instrumental to resolving the dispute about how things exist through time. ${ }^{36}$ Della Rocca believes that endurantism can be rejected on these grounds, as well as certain varieties of perdurantism. Yet I argue that persistence (and identity) must be primitive (and that there is no reason for thinking they cannot be). Della Rocca

36 See Della Rocca (2011: pp. 593, 615). 
is, then, incorrect to hold it is sufficient grounds to reject an account of persistence that that account entails that persistence is primitive. On the contrary, the correct account must entail that persistence is primitive. What the correct account is, though, cannot, I think, be resolved without first determining what the structure of temporal reality is, whether it includes many equally real moments or just one. Thus, the question of persistence in general depends on a broader investigation of the metaphysics of time.

In light of primitivism, a consequence of each thing being fundamental, one can get some sense of how such an investigation should go: one would have to get clear on what time is and how it relates to other things (such as moments and temporal entities). This is how ontological inquiry in general should proceed. All there is is (fundamental) things — no thing more real than another, no thing prior to another-standing in certain relations. Some of these relations are essential, arising from the mere existence of the things so related; some of the relations are not. What is in need of explanation, and susceptible to it, are those arrangements that need not be simply given the existence of what is so arranged, and what remains an open question is exactly what things there are in the world. Any search for the most fundamental things or for an explanation of a thing per se or of how a thing is essentially_including how it is itself_-is misguided. ${ }^{37}$

Open Access This article is licensed under a Creative Commons Attribution 4.0 International License, which permits use, sharing, adaptation, distribution and reproduction in any medium or format, as long as you give appropriate credit to the original author(s) and the source, provide a link to the Creative Commons licence, and indicate if changes were made. The images or other third party material in this article are included in the article's Creative Commons licence, unless indicated otherwise in a credit line to the material. If material is not included in the article's Creative Commons licence and your intended use is not permitted by statutory regulation or exceeds the permitted use, you will need to obtain permission directly from the copyright holder. To view a copy of this licence, visit http://creativecommons.org/licenses/by/4.0/.

\section{References}

Butler, J. (1736). Of personal identity, In The analogy of religion, natural and revealed, to the constitution and course of nature, relevant passages reprinted in Perry 2008.

Chisholm, R. (1989). On metaphysics. University of Minnesota Press.

Chisholm, R. (1976). Person and object: A philosophical study. Open Court Publishing.

Davidson, D. (1980). Essays on actions and events. Clarendon Press.

Della Rocca, M. (2011). Primitive persistence and the impasse between three-dimensionalism and fourdimensionalism. Journal of Philosophy, 108, 591-616.

Dummett, M. (1981). The interpretation of Frege's philosophy. Harvard University Press.

Dummett, M. (1973). Frege: Philosophy of language. Duckworth.

Duncan, M. (2020). A renewed challenge to anti-criterialism. Erkenntnis, 85, 165-182.

Dummett, M. (2014). A challenge to anti-criterialism. Erkenntnis, 79, 283-296.

Fiocco, M. O. (2019a). Each thing is fundamental: against hylomorphism and hierarchical structure. American Philosophical Quarterly, 56, 289-301.

Fiocco, M. O. (2019b). What is a thing? Metaphilosophy, 50, 649-669.

\footnotetext{
37 This paper was presented at the 2018 New England Workshop on Metaphysics (Identity and Persistence), organized by Matt Duncan and held at Rhode Island College. I would like to thank the audience there for insightful discussion, especially Michaela McSweeney, the commentator on the paper. Michaela, Matt and Trenton Merricks provided written comments, for which I am tremendously grateful. These comments, as well as those from two anonymous referees for this journal, were instrumental in improving the paper. I would also like to express my gratitude to Yuval Avnur and Duncan Pritchard for many helpful discussions as I was writing it.
} 
Fiocco, M. O. (2015). Intentionality and realism. Acta Analytica, 30, 219-237.

Frege, G. (1884). The foundations of arithmetic: A logico-mathematical enquiry into the concept of number, J.L. Austin (trans.). Blackwell.

Gasser, G., \& Stefan, M. (Eds.). (2012). Personal identity: Complex or simple? Cambridge University Press.

Geach, P. (1980). Reference and generality (3rd ed.). Cornell University Press.

Geach, P. (1972). Logic matters. Basil Blackwell.

Kim, J. (1994). Explanatory knowledge and metaphysical dependence. Philosophical Issues, 5, 51-69.

Kripke, S. (1980). Naming and necessity. Basil Blackwell.

Langford, S. (2017). A defense of anti-criterialism. Canadian Journal of Philosophy, 47, 613-630.

Lewis, D. (1986). On the plurality of worlds. Basil Blackwell.

Lowe, J. (2012). The probable simplicity of personal identity. Gasser and Stefan, 2012, 137-155.

Lowe, J. (2009). More kinds of being: A further study of individuation, identity, and the logic of sortal terms. Wiley-Blackwell.

Lowe, J. (1998). The possibility of metaphysics: Substance, identity and time. Clarendon.

Madell, G. (1981). The identity of the self. Edinburgh University Press.

Merricks, T. (1998). There are no criteria of identity over time. Noûs, 32, 106-124.

Perry, J. (Ed.). (2008). Personal identity. University of California Press.

Van Quine, W. O. (1969). Speaking of objects. In W. V. Quine, Ontological relativity and other essays. Columbia University Press.

Van Quine, W. O. (1953). On What There Is. In W. V. Quine, From a logical point of view. Harvard University Press.

Reid, T. (1785). Essays on the intellectual powers of man, relevant passages reprinted in Perry 2008.

Ruben, D.-H. (1990). Explaining explanation. Routledge.

Shoemaker, S. (2012). Against simplicity. Gasser and Stefan, 2012, 123-136.

Strawson, P. (1959). Individuals. Routledge.

Swinburne, R. (1985). Personal identity: The dualist theory. In S. Shoemaker \& R. Swinburne, Personal identity. Basil Blackwell.

Thomasson, A. (2007). Ordinary objects. Oxford University Press.

van Inwagen, P. (1990). Material beings. Cornell University Press.

Wiggins, D. (1980). Sameness and substance. Basil Blackwell.

Wiggins, D. (1967). Identity and spatiotemporal continuity. Basil Blackwell.

Williamson, T. (1990). Identity and discrimination. Basil Blackwell.

Wittgenstein, L. (1953). Philosophical Investigations. In G.E.M. Anscombe \& R. Rhees (Eds.), G.E.M. Anscombe (trans.), Blackwell.

Zimmerman, D. (1998). Criteria of identity and the 'identity mystics.' Erkenntnis, 48, 281-301.

Publisher's Note Springer Nature remains neutral with regard to jurisdictional claims in published maps and institutional affiliations. 